Nutritional Improvement

for children in urban

Chile and Kenya

BRIEFING PAPER 7

NICK

(Nutritional Improvement for children in urban Chile and Kenya) ${ }^{1}$

\section{A social determinants approach to tackling chronic child malnutrition in urban informal settlements in Chile and Kenya}

Professor Pat Pridmore

Institute of Education, University of London

This Briefing Paper highlights the need for action to change the social determinants of chronic child malnutrition and describes research being undertaken by the NICK Project.

It identifies social determinants in informal urban settlements and slums in developing countries and outlines some of the pathways involved.

It summarises evidence on effective programming by drawing on findings from the review entitled 'Nutritional

1 The NICK Project partners are the Institute of Education, University of London (Prof. Pat Pridmore (Director), Dr. Tristan McCowan, Prof. Roy Carr-Hill); the International Centre for Reproductive Health (ICRH) Kenya (Dr. Mary Nyamongo, Mr. Daniel Lang'o ; the University of Valparaíso, Chile, Department of Public Health (Prof. Gabriela Charnes, Dr. Beatriz Salgado.

The advisory group members are Dr. Shahnaz Kassam Sharif, Director of Public Health, Ministry of Public Health and Sanitation, Kenya; Prof. Marleen Temmerman, Chair of Board, ICRH Kenya; Dr. Kirsten Haveman, Counsellor (Health), DANIDA, Mozambique; Prof. Oscar Arteaga, Dean, School of Public Health, University of Chile; Dr.Jaime Jamett Rojas, Director, Regional Secretariat of Health of Valparaíso, Chile. improvement for children in poor urban areas of developing countries: A cross national review of the evidence for action on the social determinants' (Pridmore, 2010) which can be found on the NICK website at at http://nick.ioe.ac.uk

It also identifies key lessons learned.

\section{Introduction}

The rapid, unplanned increase in the urban population is one of the most important global health issues of the $21^{\text {st }}$ century. It has caused widespread social inequity and stratification resulting in more than half the urban residents in many lowincome countries living in informal settlements or slums (World Bank, 2009; Martin-Prevel et al., 2000).

In these poor urban areas child undernutrition is endemic jeopardizing the physical and mental development of young children and impacting national development (Grantham-McGregor et al., 2007, Victora et al., 2008). At the same time the emerging generation of overweight children has been dubbed an 'obesity time-bomb' predisposing to adult obesity with increased risk of morbidity and mortality from chronic diseases and demand for services (Mitchell, 2010).

Political interest in taking action to reduce chronic child malnutrition in a sustainable way has been heightened by the need to get the Millennium Development Goals (MDGs) $^{2}$ back on track. It has also been heightened by the report from the WHO Commission on the Social Determinants of Health (WHO, 2008), which concluded that 'Social inequities are killing people on a grand scale' (p.248) and identified nutrition as a critical governance issue. Heads of Government, Ministers and government representatives from 125 WHO Member States have expressed global political commitment for the implementation of the social determinants approach to health improvement inequities by adopting the Rio Political Declaration on Social Determinants of Health (WHO, 2011).

\footnotetext{
${ }^{2}$ Adequate nutrition is a crucial input to the first six Millennium Development Goals (MDGs) (Save the Children 2009).
} 
The social determinants approach seeks to change the social, economic, educational and environmental factors that operate at the national, municipal and household levels in order to improve the everyday living conditions and behaviours of poor families. In urban areas, municipal governments are uniquely positioned to play a leading role in finding these solutions through broadening stakeholder participation to change both upstream and downstream determinants (Libman et al., 2010, KNUS, 2008). The NICK Project (described below) is facilitating and supporting action research to seek these solutions.

\section{The NICK ${ }^{3}$ Project}

This is a 3 year research study which started in October 2010 with funding from the UK Government Department for International Development and the UK Economic and Social Research Council. It aims to help the cities of Mombasa in Kenya and Valparaíso in Chile to reduce chronic child malnutrition in a sustainable way. To achieve this aim it has established a multidisciplinary team in each study city to broaden stakeholder participation and change the social determinants.

These two cities are experiencing high levels of malnutrition amongst the urban poor. A baseline survey conducted by the project researchers in two informal settlements in Mombasa by the NICK Project in 2011 has found that $21 \%$ of boys and $14 \%$ of girls were severely stunted and $43 \%$ of boys and $40 \%$ of girls were moderately stunted. A contrasting situation is found in Valparaíso. Although the baseline survey is still ongoing, statistics from the Regional Health Office of Valparaíso show that $9 \%$ of pre-school children attending primary health clinics are overweight, and $20.6 \%$ of school children in Grade One are obese.

In the first year of the study, the research team in each city has:

\footnotetext{
${ }^{3}$ Nutritional Improvement for Children in Urban Chile and Kenya (NICK)
}

i. Conducted background literature reviews and situational analyses;

ii. Identified an intervention and a control area in informal settlements;

iii. Collected baseline data through anthropometric and household surveys;

iv. Established a multidisciplinary participatory action research (PAR) group with members from all nutrition-related line ministries, civil society and the intervention community;

v. Facilitated action research workshops for the teams to share their experiences and the preliminary findings from the baseline survey. These workshops have also sought to stimulate new ways of thinking about child malnutrition and find new ways for team members to work together to change the social determinants and develop multisectorial action plans.

During the next two years the researchers will continue to facilitate and support the work of these multisectoral teams through three sixmonthly cycles of analysis, planning, action and reflection to monitor implementation of their activities and increase the effectiveness of their collaborative actions. Data to monitor implementation of the action plans and to inform any process of change in the way the PAR group members think about undernutrition, interact with each other and form new partnerships will also be collected. Follow-up anthropometric and household survey data will then be collected to inform the impact evaluation, and the findings will be widely disseminated to inform policy and practice.

In Mombasa the research will be extended to develop a case study to explore how to tackle chronic child undernutrition in young children of mothers subjected to domestic violence. In Valparaíso the research will be extended to develop a case study of how to tackle chronic child overweight and obesity through 
working with food market traders and members of the fishing industry.

The outputs from the NICK Project (including the structured literature review which this briefing paper draws on) are available on the project website.

\section{The social determinants of chronic child malnutrition in urban areas}

Ruel (1999) identified five key social determinants of child malnutrition in informal urban settlements and slums:

i. Greater dependence on cash income but high levels of unemployment leading to increased poverty and poor living conditions;

ii. Weaker informal social safety nets and greater labour force participation of women leading to poor child care practices;

iii. Lifestyle changes leading to changes in diet and exercise patterns;

iv. Greater availability of public services, but questionable access by the poor;

v. Governance by a new, possibly nonexistent, set of property rights.

These determinants map onto the framework in Figure 1 developed to guide the work of the WHO Commission on the Social Determinants of Health. This framework shows that improving child nutrition at the municipal level means intervening to change multiple social, economic and environmental factors operating at different levels.

Some of the key pathways leading to child malnutrition that have been identified are: i. Lack of access to central (super) markets due to public transport costs and the need to buy poor quality food from small local shops at higher prices (Sanders and Puoane, 2010; Lane et al., 2008; Lovasi et al., 2009; Galal et al., 2010);

ii. Little time to prepare food, no suitable space for cooking and no money for cooking fuel and difficulties in adapting to new staple foods (KNUS, 2008);

iii. Reduced spending on food due to competing demands for transport to work, rent for housing, and remittances to relatives in the rural areas. (Lovasi et al., 2009);

iv. Spending on televisions, cars and the 'fast foods' that are highly profitable when widely available and heavily promoted directly to children (Moodie, R., B. Swinburn, et al., 2006);

v. Social norms and child feeding practices that associate large body size with power, beauty, and affluence (Wu et al., 2009, Fitzgibbon and Beech, 2009);

vi. Domestic violence against mothers and crime leading to stress and maternal depression, a risk factor for poor infant growth. (Ackerson and Subramanian, 2008; Stewart, 2007);

vii. Inadequate physical activity linked to changes in occupational and leisure activities and lack of safe recreational spaces (Cutts et al., 2009). 


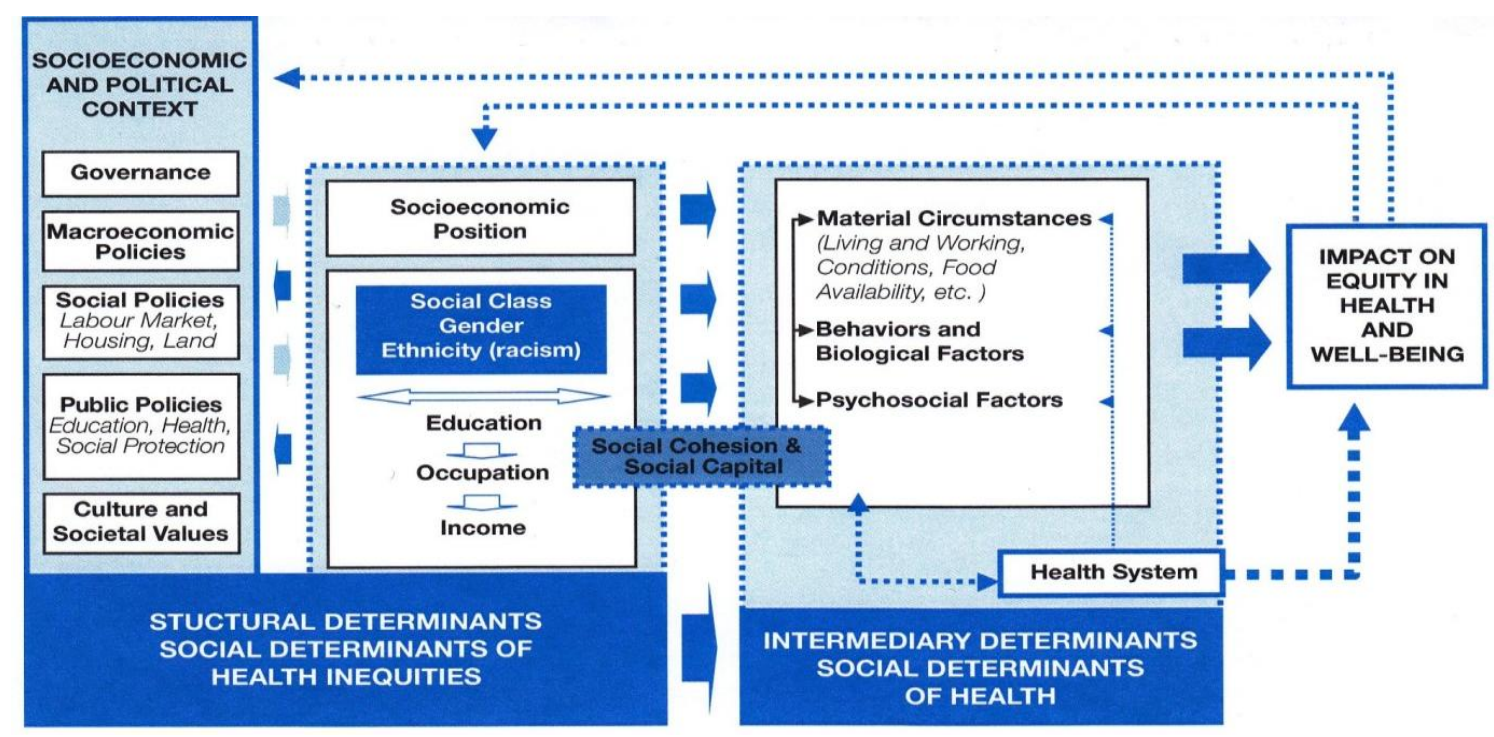

Figure 1 Conceptual framework for action on social determinants of health and nutrition (WHO, 2010, p.48)

viii. Poor governance leading to lack of pro-poor economic, social and public health policies including those that influence urban planning and employment.

ix. Lack of control over markets and food companies unwilling to support social health and nutrition goals.

$x$. Negative social norms and values relating to body size.

\section{Effective programming to change the social determinants?}

Given the complex nature of the social determinants of child undernutrition interventions at the municipal level need to be multisectoral and multi-level. Such interventions are difficult to evaluate; they are often diffuse and community based and always context specific. Many interventions have not been effectively evaluated and the evidence base is ambiguous. Nevertheless, there is evidence to support the following approaches which require co-ordinated action at the municipal level rather than large inputs of development aid.

Community wide interventions to create a more enabling environment for behaviour change. Interventions focusing solely on individual behaviour change have met with very limited success (Flynn et al., 2006; Kain et al., 2008, Summerbell et al.,
2005). However, effective interventions to combat obesity have developed coordinated actions to reduce food prices, regulate food outlets, change food trade policy and control urban planning (LobCorzilius, 2007, Hughes and Reilly, 2008, Sanders and Puoane, 2010). A WHO (2009) review of 65 community wide interventions to address obesity concluded that the most successful comprised many different activities (Sassi, 2010).

Strengthening food security through promoting urban agriculture and home gardening: These interventions have increased the diversity of children's diets and reduced micronutrient deficiencies (Bhattacharjee, Kumar, \& Nandi, 2007); they can also lead to the empowerment of women (Bushamuka et al., 2005; World Bank \& IFPRI, 2007) and be used to integrate agriculture and primary health activities (Faber et al., 2002). In the face of family breakdown fostering women's social ties and networks can increase food security and child nutritional status (see for example Lemke et al., 2003).

Government regulation and fiscal levers (such as taxes on high fat and/or sugar foods) have had limited success (Bonefoy, 2010). Overconsumption by children of 'fast-foods' (high in sugar and fat) reflects commercial success but failure of the market to self-regulate in order to sustain and promote social and individual goals. 
There have been calls for local government intervention to work more with 'fast-food' outlets, television advertisers etc. than with consumers and provide some form of 'watchdog' to improve business accountability (Kim and Kawachi, 2006, Moodie et al., 2006, Doane, 2004, James, 2008, Cuevas et al., 2009).

Strengthening democratic governance: The growth of urban informal settlements and slums is evidence of a failure of municipal governance ${ }^{4}$ impacting child under- and over-nutrition. A study by Rokx (2006) found that countries with higher governance scores have lower rates of child undernutrition. She also found that in Madagascar 'voice' can be created through building local support and creating demand for improved nutrition and that lower levels of undernutrition can be achieved when this voice is used to increase political commitment, accountability and financing for nutrition.

A broad range of strategies to combat child obesity have been identified (related to the governance of land use, food, parks

\section{Key lessons learned}

Child malnutrition cannot be tackled by any one sector alone. For sustainable improvements a social determinants approach is needed.

In urban areas, multisectorial teams at the municipal level are uniquely positioned to play a leading role in designing and implementing the complex interventions needed to change both upstream and downstream social determinants; through broadening community participation and 'voice' and strengthening democratic governance to reduce social inequities.

These complex, multisectorial interventions are needed to improve the everyday living conditions, food security and behaviours influencing dietary patterns, child care practices, access to health services, water and sanitation and stress levels of families living in informal urban settlements.

The challenge for the NICK Project is how to make cross-sectorial collaboration work most effectively and to robustly evaluate and explain any impact on child malnutrition. and green space, transportation and schools). These strategies can be enacted at the municipal level to reduce socioeconomic and racial/ethnic inequalities in obesity (Libman et al. 2010).

Broadening community participation to give the urban poor a voice: A controlled evaluation of an intervention in Kenya showed that undernutrition in 1-5 year olds could be significantly reduced by using a social educational process known as participatory learning and action (PLA) to strengthen social cohesion for collective action; and by increasing community access to nutrition-related public services (Haveman, 2005). However, an extensive review by Ismail et al. (2003) concluded that participation for empowerment must be embedded within community-driven programmes in an enabling environment provided by policies and interventions at all levels.

\section{References}

ACKERSON, L. K. \& SUBRAMANIAN, S. V. (2008) Domestic Violence and Chronic Malnutrition among Women and Children in India. American Journal of Epidemiology, Volume167, 11881196.; Stewart, 2007).

BHATTACHARJEE, L., KUMAR, S. K., \& NANDI, B. (2007). Food-based nutrition strategies in Bangladesh: Experience of integrated horticulture and nutrition development

BUSHAMUKA, V. N., DE PEE, S., TALUKDER, A., KIESS, L., PANAGIDES, D., TAHER, A., \&

BLOEM, M. (2005). Impact of a homestead gardening program on household food security and empowerment of women in Bangladesh. Food and Nutrition Bulletin, 26(2), 17-25.

BONEFOY, P. (2010) Combating Chile's exploding obesity rates. World News from Global Post, Cutts et al., 2009

CUEVAS, A., ALVAREZ, V. \& OLIVOS, C. (2009) The emerging obesity problem in Latin America. Expert Review of Cardiovascular Therapy, 7, 281-8.

DOANE, D. (2004) Beyond corporate social responsibility, minnows, mammoths and markets. Futures 37, 215-229.

FABER, M., PHUNGULA, M. A. S., VENTER, S. L., DHANSAY, M. A., \& BENADE, 
A. J. S. (2002). Home gardens focusing on the production of yellow and dark-green leafy vegetables increase the serum retinol concentrations of 2-5-y-old children in South Africa. American Journal of Clinical Nutrition, 76(5), 1048-1054.

FITZGIBBON, M. L.BEECH, B. M. (2009) The Role of Culture in the Context of School-Based BMI Screening. Pediatrics, 124, S50-S62.

FLYNN, M. A. T., MCNEIL, D. A., MALOFF, B., MUTASINGWA, D., WU, M., FORD, C. \& TOUGH, S. C. (2006) Reducing obesity and related chronic disease risk in children and youth: a synthesis of evidence with 'best practice' recommendations. Obesity Reviews, 7 Suppl 1, 7-66.

GALAL, O., CORROON, M. \& TIRADO, C. (2010) Urban environment and health: food security. Asia-Pacific Journal of Public Health, 22, 254S-261S.

KAIN, B. J., UAUY, D. R., LERA, M. L., TAIBO, G. M., ESPEJO, F. \& ALBALA, B. C. (2005) Evolution of the nutritional status of six years old Chilean children (1987-2003). [Spanish]

GRANTHAM-MCGREGOR, S., CHEUNG, Y. B., CUETO, S., GLEWWE, P., RICHTER, L. \& STRUPP, B. (2007) Developmental potential in the first 5 years for children in developing countries. Lancet, 369, 60-70.

HAVEMAN, K. (2005) Effective Participation for Health Development. London, Unpublished PhD thesis, Institute of Education, University of London, London.

HUGHES, A. R. \& REILLY, J. J. (2008) Disease management programs targeting obesity in children: Setting the scene for wellness in the future. Disease Management and Health Outcomes, 16, 255-266.

JAMES, W. P. T. (2008) The epidemiology of obesity: the size of the problem. Journal of Internal Medicine, 263, 33652.

LANE, S. D., KEEFE, R. H., RUBINSTEIN, R., LEVANDOWSKI, B. A., WEBSTER, N., CIBULA, D. A., BOAHENE, A. K., DELE-MICHAEL, O., CARTER, D., JONES, T., WOJTOWYCZ, M. \& BRILL, J. (2008) Structural violence, urban retail food markets, and low birth weight. Health \& Place, 14, 415423.

LOVASI, G. S., HUTSON, M. A., GUERRA, M. \& NECKERMAN, K. M. (2009) Built Environments and Obesity in Disadvantaged Populations. Epidemiologic Reviews, 31, 7-20.
LEMKE, S., VORSTER, H. H., VAN RENSBURG, N. S. J. \& ZICHE, J. (2003) Empowered women, social networks and the contribution of qualitative research: broadening our understanding of underlying causes for food and nutrition insecurity. Public Health Nutrition, 6, 759-64.

LIBMAN, N. K., FREUDENBERG, N. \& O'KEEFFE, E. (2010) A tale of two obesCities: the role of municipal governance in reducing childhood obesity in New York City and London 87(5): Journal of Urban Health, 75570.

LOB-CORZILIUS, T. (2007) Overweight and obesity in childhood--a special challenge for public health. International Journal of Hygiene \& Environmental Health, 210, 585-9.

KIM, D. and KAWACHI, I. (2006) Food taxation and Pricing Strategies to "thin out" the obesity Epidemic. American Journal of Preventive Medicine, 30 (5), 430-437.

KNUS (2008) Our cities, our health, our future: Acting on social determinants for health equity in urban settings. Report from the Knowledge Network on Urban Settings (KNUS). . Kobe.

MARTIN-PREVEL, Y., MAIRE, B. \& DELPEUCH, F. (2000) [Nutrition, urbanization and poverty in subsaharan Africa]. Medecine Tropicale, 60, 179-91.

Mitchell, F. (2010) Child obesity 'time bomb'. Nursing Times, 30 ${ }^{\text {th }}$ October 2010. Available at

http://www. nursingtimes.net/nursingpractice-clinical-research/clinicalsubjects/obesity/child-obesity-timebomb/5021129.article

MOODIE, R., SWINBURN, B., RICHARDSON, J. \& SOMAINI, B. (2006) Childhood obesity--a sign of commercial success, but a market failure. International Journal of Pediatric Obesity, 1, 133-8.

ROKX, C. (2006) Governance and Malnutrition: Exploring the Contribution of 'Good Governance' to Malnutrition Reduction in Developing Countries. Faculty of Law. Enschede, , University of Maarstricht, The NetherlandsRuel (1999)

SANDERS, D. \& PUOANE, T. (2010) Obesity and overweight in South Africa: Trends, causes and required interventions. Obesity Reviews, Conference: 11th International Congress on Obesity, ICO 2010 Stockholm Sweden. Conference Start: 20100711 Conference End: 
20100715. Conference: 11th International Congress on Obesity, ICO 2010 Stockholm Sweden. Conference Start: 20100711 Conference End: 20100715. Conference Publication: (var.pagings). $11,22$.

SASSI, F. (2010) Obesity and the economics of prevention Organisation for Economic Co-operation and Development (OECD).

SUMMERBELL, C. D., WATERS, E., EDMUNDS, L. D., KELLY, S., BROWN, T. \& CAMPBELL, K. J. (2005) Interventions for preventing obesity in children. Cochrane Database of Systematic Reviews.

TAHER, A., \& BLOEM, M. (2005). Impact of a homestead gardening program on household food security and empowerment of women in Bangladesh. Food and Nutrition Bulletin, 26(2), 17-25.

VICTORA, C., ADAIR, L., FALL, C., HALLAL, P. C., MARTORELL, R., RICHTER, L. \& SACHDEV, H. S. (2008) Maternal and child undernutrition: consequences for adult health and human capital The Lancet, 371, 340 357.

WHO (2008) Closing the gap in a generation: Health equity through action on the social determinants of health. Report of the WHO Commission on the Social Determiants of Health. Geneva, WHO.

WHO (2010) A conceptual framework for action on the social determinants of Health. Geneva, WHO.

WHO (2011) Rio Political Declaration on Social Determinants of Health. Geneva: WHO. Available at http://www.who.int/sdhconference/decl aration/Rio_political_declaration.pdf World Bank, \& IFPRI. (2007). From Agriculture to Nutrition: Pathways, Synergies and Outcomes.

Washington, DC: World Bank

WORLD BANK (2009) World Bank, urban and local government strategy. Washington, The World Bank.

WU, Y., HUXLEY, R., LI, M. \& MA, J. (2009) The growing burden of overweight and obesity in contemporary China. CVD Prevention and Control, 4, 19-26 